\title{
Roles of context in acquisition of human instrumental learning: Implications for the understanding of the mechanisms underlying context-switch effects
}

\author{
A. Matías Gámez ${ }^{1,2}$ • Samuel P. León ${ }^{1}$ • Juan M. Rosas ${ }^{1}$
}

Published online: 30 December 2016

(C) Psychonomic Society, Inc. 2016

\begin{abstract}
Four experiments in human instrumental learning explored the associations involving the context that develop after three trials of training on simple discriminations. Experiments 1 and 4 found a deleterious effect of switching the learning context that cannot be explained by the contextoutcome binary associations commonly used to explain context-switch effects after short training in human predictive learning and in animal Pavlovian conditioning. Evidence for context-outcome (Experiment 2), context-discriminative stimulus (Experiment 3), and context-instrumental response (Experiment 4) binary associations was found within the same training paradigm, suggesting that contexts became associated with all the elements of the situation, regardless of whether those associations played a role in a specific context-switch effect detected on performance.
\end{abstract}

Keywords Contents of learning · Context-switch ·

Instrumental conditioning $\cdot$ Humans

Performance is usually impaired when it is tested outside the context in which the original learning takes place, both in human and in non-human animals (e.g. Baddeley, 1982; Godden \& Baddeley, 1975; Nelson, 2002; Rosas, GarcíaGutiérrez, \& Callejas-Aguilera, 2007; Rosas, Vila, Lugo, \& López, 2001; Tulving \& Osler, 1968; for a review see Bouton, 1993; Rosas, Todd \& Bouton, 2013). In these situations, contexts may control behavior through direct associations with the outcome $(\mathrm{O})$, competing with the conditioned stimulus

Juan M. Rosas

jmrosas@ujaen.es

1 Department of Psychology, Universidad de Jaén, 23071 Jaén, Spain

2 University of Cádiz, Cádiz, Spain
(CS) for the associative strength (e.g., Mackintosh, 1975; Pearce \& Hall, 1980; Rescorla \& Wagner, 1972; i.e. León, Abad, \& Rosas, 2011) or being part of a configuration that includes the CS or the discriminative stimulus, and that it is associated with the outcome as a whole (e.g., Pearce, 1987; Wagner, 2003; see also Darby \& Pearce, 1995). Moreover, contexts may also play the role of modulators, controlling behavior through hierarchical associations in which the context regulates the relationship among stimuli, outcomes, and responses (i.e., occasion setter, see e.g., Holland, 1983; see also Bouton, 2004; Bouton \& Swartzentruber, 1986, for an application to contextual control). Research on contextual control has focused on establishing the specific association involving context that explains context dependence of the information in a given situation. Alternatively, context effects may depend not so much on which association is established, but on which of the established associations are expressed. The credit of this alternative approach depends on whether the different associations involving context are concurrently established. The main goal of this experimental series was to test this latter idea, with the ultimate goal of shedding light on whether future research in contextual control should focus on determining the conditions that lead to the formation of different associations involving context, or on the conditions that lead to the expression of a specific association among the ones that are automatically established.

In the studies suggesting that contexts control behavior through simple binary associations, focus has been placed mostly on the potential association between the context and the outcome (for a review see Bouton, 2010; Urcelay \& Miller, 2014), disregarding other binary associations that may also play a role in controlling performance (e.g., Colwill, 1994; Gámez \& Rosas, 2007). From this perspective, switching the context leads to a decrease in the associative strength accrued by the new stimulus compound (CS+New 
Context) presented at testing, and explains the decrease in conditioned responding related to the context switch (e.g., León et al., 2011; León, Callejas-Aguilera, \& Rosas, 2012; Moreno-Fernández, Abad, Ramos-Álvarez, \& Rosas, 2011; Murphy, Baker, \& Fouquet, 2001). For instance, León et al. (2011) explored the role of the length of training on the context-switch effect within a human predictive learning task. Participants were trained in an imaginary situation in which clients of a restaurant suffered an illness when ingesting a specific target food $X$. At the same time, clients of a different restaurant did not suffer illnesses when eating target food Y. One group of participants received four trials of training with each stimulus in each restaurant, while a different set of participants received 18 trials with each stimulus. Participants receiving four trials of training were sensitive to the context change at testing, while participants receiving 18 trials were not. The context change led to a decrease in responding to the stimulus that was followed by the outcome $(\mathrm{X})$ coupled with an increase in responding to the stimulus that was not followed by the outcome (Y). This symmetrical effect of switching the context disappeared when the outcome was presented in both contexts, reappearing when one of the contexts was later extinguished. Taken together, these results suggest that the context-switch effect was based on the formation of contextoutcome associations at the beginning of training, that are extinguished when training is extended. Note that conditioning seems to be context-dependent after extended training in some situations (e.g., Bouton, Frohardt, Sunsay, Waddell, \& Morris, 2008; Pickens, Golden, Adams-Deutsch, Nair, \& Shaham, 2009; Urcelay, Witnauer, \& Miller, 2012), though this effect seems to be more the exception than the rule (see Bouton, 1993, 1994).

A related study conducted by León, Abad, and Rosas (2010b) replicated the effect of the length of training on the context-switch effect in human instrumental learning. Participants played a computer task in which they had to make one of two responses in the presence of different colored discriminative stimuli within different visually distinct background contexts. Two different responses (R1 and R2) were followed by two different outcomes (O1 and $\mathrm{O} 2)$ in the presence of different stimuli (X, Y, Z, and R) within two different contexts ( $\mathrm{X}$ and $\mathrm{Y}$ in Context $\mathrm{A}$ and $\mathrm{Z}$ and $\mathrm{R}$ in Context $\mathrm{B}$ ). In agreement with the results summarized above, the change in the context attenuated performance in participants who received three training trials, but not in those participants who received five or eight training trials before the context-switch took place. Contrary to what it was found within the predictive learning situation, in an instrumental situation the context switch effect appeared when the same outcomes were delivered in both contexts, precluding the possibility of explaining the difference at testing in terms of differential contextoutcome associations. Responses were also reinforced in both contexts, so the context-switch effect could not be explained by the loss of a context-response association. León et al. (2010b) concluded that the type of association that it is more likely to underlie their results is a hierarchical, occasionsetting-type one (see also León, Abad, and Rosas, 2010a). However, they did not discuss the possible contribution to the context-switch effects of other binary associations, such as configural, or context-stimulus associations that might have been involved given the relatively small number of trials (three).

Context-switch effects on performance may be due to different mechanisms within similar experimental designs, perhaps depending on the specific conditions of the experimental setting, the type of task used, etc. For instance, Urcelay and Miller (2010) found trial spacing as a critical parameter determining whether contexts would play the role of conditioned stimuli or retrieval stimuli in fear conditioning, and other critical factors may be relevant in other situations (see also Miguez, Witnauer, Laborda, \& Miller, 2014). Even more, it is possible that in situations in which the deleterious effect of changing the context is based on a specific role, the context may also play alternative roles that may be behaviorally silent under specific testing conditions, but that may be observed if testing conditions were changed. In other words, it is possible that in any given situation contexts enter into all the different binary and hierarchical associations. If that were the case, the experimental situation would not determine which association is established, but which one is expressed. The experimental series that we present here was conducted as a first test of this hypothesis, focusing on the analysis of the binary associations that seem more likely to develop within short training situations. The short training discrimination situation was chosen because context-switch effects after short training are quite consistent across different procedures and species, but the mechanisms underlying them seem to be different in different situations, going from direct context-outcome associations (e.g., León et al., 2011) to contexts potentially playing the role of occasion setters (e.g., Hall \& Honey, 1990; León et al., 2010b).

Accordingly, the main goal of the present study was to explore whether short training on an instrumental discrimination leads to the formation of different binary associations between the context and the other three elements involved in the situation: outcome, stimulus, and response. Finding evidence of the formation of different associations within the same learning situation would set the grounds for directing the research on the mechanisms of contextual control towards the conditions that lead to the expression of a given association, rather than towards the conditions that lead to the formation of the different associations.

Experiment 1 explored the role of direct context-outcome associations on context-switch effects after acquisition of an instrumental discrimination. The instrumental conditioning design used by León et al. (2010b) was modified to make it 
similar to the one used by León et al. (2011) in a human predictive learning task. They presented the outcome only in one of the contexts used in their study and that allowed them to conclude that context-switch effects were based on contextoutcome associations. As no clear evidence of contextoutcome associations was found in Experiment 1, Experiments 2-4 were conducted with the goal of exploring whether the different binary associations between the context and the outcome were established within the same basic situation, regardless of whether those associations play a role in the context-switch effect consistently found in the short training situation. To explore these associations, we used transfer tests that have shown their usefulness to detect binary associations that otherwise would go undetected if only the conditioned response is recorded (e.g., Delamater, 1996; Colwill \& Rescorla, 1988; Gámez, Martos, Abad, \& Rosas, 2013; Gámez \& Rosas, 2007; Nadler, Delgado, \& Delamater, 2011).

\section{Experiment 1}

The studies conducted by León et al. (2010b, 2011) regarding the effects of switching the context after different lengths of training show that the same context-switch effect may be explained by different underlying mechanisms in two different tasks. Aside from the use of two different procedures, additional differences between the two studies were noteworthy. León et al. (2011) used a predictive learning task with a design that involved presenting the outcome only in one of the contexts, but not in the other. However, León et al. (2010b) used an instrumental learning task that involved presenting two outcomes the same number of times in the two contexts used. Accordingly, the explanation in terms of direct contextoutcome associations given for the context-switch effect reported in the first study was not relevant in the second one.

The goal of Experiment 1 was to follow up on the study conducted by León et al. (2010b) by exploring whether context-outcome associations may underlie context-switch effects after short training in a human instrumental discrimination. As shown in Table 1, participants were reinforced for performing R1 in the presence of X in Context A (A: X:R1$\mathrm{O})$. Responding in the presence of any other stimulus was not reinforced, regardless of whether the stimulus was presented in context $\mathrm{A}(\mathrm{Z})$ or in Context $\mathrm{B}$ ( $\mathrm{Y}$ and $\mathrm{J}$ ). In the subsequent test, participants had the opportunity of performing R1or R2 in the presence of target stimuli $\mathrm{X}$ and $\mathrm{Y}$ in contexts $\mathrm{A}$ and $\mathrm{B}$ (in the same context where they were trained, or in a different, but equally familiar context).

According to the results reported by León et al. (2010b), responding in the presence of $\mathrm{X}$ should be lower in context different (B) than in context same (A). The key observation here refers to performance in the presence of the nonreinforced discriminative stimulus $\mathrm{Y}$ with the context change.
Responding was reinforced only in context A, so that only context A could be associated with the outcome (see León et al., 2011). If the context-switch effect was at least partially based on a direct association between the context and the outcome presented on it, the effect of context change expected on $\mathrm{X}$ should be reversed on $\mathrm{Y}$. That is, responding in the presence of $\mathrm{Y}$ should be greater in context $\mathrm{A}$ than in context $\mathrm{B}$, given that the outcome was only presented in context $\mathrm{A}$ (see León et al. 2011).

\section{Method}

\section{Participants}

Twenty-four undergraduate students ( 16 from the Universidad de Jaén and eight from the University of Cádiz) participated in this experiment in exchange for course credit ( 22 women, two men; $M_{\text {age }}=21.03$ years; age range $=18-31$ years). They had no previous experience with this task. All participated voluntarily and gave their informed consent before starting the experiment, being free to abandon the task at any point of the process, though that never happened. Previous studies with this type of procedure have used sample sizes smaller than the one used here (e.g., Gámez \& Rosas, 2005, 2007; León et al., 2010b). A larger sample size was used here to increase the statistical power of the designs.

\section{Apparatus and stimuli}

Participants were trained individually in six adjacent isolated cubicles. Each cubicle had a Pentium PC on which the task was presented. The procedure was implemented using the program SuperLab Pro (Cedrus Corporation) software. The task was identical to the one used by León et al. (2010b). Participants played a computer game in which they had to defend Andalusia from air and land attacks. The main screen represented a viewer simulating participants' view from a hypothetical bunker. On top of the screen there were four rectangles that could be colored. Red, navy blue, light blue, and gray colors were counterbalanced as discriminative stimuli X, $\mathrm{Y}, \mathrm{Z}$, and J. Contexts were presented within the viewing area of the viewer. Scenes of different beaches of Andalusia, Puerto Banús (urban beach), and Tarifa (natural beach) were counterbalanced as contexts A and B. The two attackers were a plane and a tank. The plane was presented in the sky, at the top right area of the context, while the tank was presented on the sand, at the bottom left area of the context. Both attackers could appear in one of two different positions within their respective areas on the context, so that it would give the impression of movement to the participant. The instrumental response was clicking on either the plane or the tank (R1 and R2, counterbalanced). Destruction of the tank and the 
Table 1 Experimental designs

\begin{tabular}{|c|c|c|c|c|}
\hline Experiment & Pre-training & Discriminative training & Context test & Association test \\
\hline 1 & & $\begin{array}{l}\text { A: 3X: R1-O1, R2- / 3Z: R1-, R2- } \\
\text { B: 3Y: R1-, R2- / 3J: R1-, R2- }\end{array}$ & $\begin{array}{l}\text { A:1X: R1-, R2- vs. B: 1X: R1-, R2- } \\
\text { A:1Y: R1-, R2- vs. B: 1Y: R1-, R2- }\end{array}$ & \\
\hline 2 & $\begin{array}{l}6 \text { R1-O1 } 6 \text { R3-O1 } \\
6 \text { R2-O2 } 6 \text { R4-O2 }\end{array}$ & $\begin{array}{l}\text { A: 3X: R1-O1, R2-/ 3Z: R1-, R2- } \\
\text { B: 3Y: R1-, R2- / 3J: R1-, R2- }\end{array}$ & & $\begin{array}{l}\text { 1A: R3 vs. R4 } \\
\text { 1B: R3 vs. R4 }\end{array}$ \\
\hline 3 & $\begin{array}{l}6 \mathrm{X}: \mathrm{R} 3-\mathrm{O} 1, \mathrm{R} 4- \\
6 \mathrm{Y}: \mathrm{R} 3-, \mathrm{R} 4-\end{array}$ & $\begin{array}{l}\text { A: 3X: R1-O1, R2- / 3Z: R1-, R2- } \\
\text { B: 3Y: R1-, R2- / 3J: R1-, R2- }\end{array}$ & & $\begin{array}{l}\text { A:1X: R3-, R4- } \\
\text { B:1X: R3-, R4- }\end{array}$ \\
\hline 4 & & $\begin{array}{l}\text { A: 3X: R1-O1, R2- / 3Z: R1-, R2- } \\
\text { B: 3Y: R1-, R2-O1 / } 3 \text { J: R1-, R2- }\end{array}$ & $\begin{array}{l}\text { A: 1X: R1-, R2- vs. B: 1X: R1-, R2- } \\
\text { A: 1Y: R1-, R2- vs. B: 1Y: R1-, R2- }\end{array}$ & $\begin{array}{l}\text { 1A: R1 vs. R2 } \\
\text { 1B: R1 vs. R2 }\end{array}$ \\
\hline
\end{tabular}

Note. Contexts A and B: Beaches of Puerto Banús and Tarifa, counterbalanced. Discriminative stimuli X, Y, Z, and J: Red, navy blue, light blue, and gray, counterbalanced. R1, R2: Clicking on the plane or the tank, counterbalanced (Experiment 1). R1, R2, R3, and R4 in the rest of experiments: Clicking on different numbered keys. O1 and O2: Plane or tank destruction, counterbalanced. Numbers indicate the amount of trials conducted with that specific trial type. Stimuli (attackers) on the association tests of Experiments 3 and 4 were different from the ones used throughout training. See text for details

plane was counterbalanced as outcome 1 (O1) across participants. Note that the image of the attacker works as a discriminative stimulus for the instrumental response (clicking on the attacker) and the expected outcome (destruction of the attacker) in this task.

\section{Procedure}

The instructions and all the necessary information were presented in participants' first language (Spanish) on the computer screen. Participants interacted with the computer using the mouse (left button). Instructions were presented in five screens using a black Times New Roman 26 bold font against a light yellow background to emulate the appearance of an old document. To advance the instruction screens, participants had to click on a button labelled as "next" placed on the right bottom of the screen. Each participant was initially asked to read the following instructions:

“(Screen 1) Andalusia is being attacked. Different parts of Andalusia are being assaulted by land and air. You are placed in the only bunker able to face up the attackers. Your work consists in protecting Andalusia. Use the mouse to throw missiles to the targets. Your goal is to destroy the attackers before they take Andalusia over. (Screen 2) The monitor represents the bunker's viewer, in which the different attackers you should face will appear. Your technology and weapons are older than theirs, so you will need to shoot several times to be able to destroy them. To shoot, click with the left button of the mouse while the pointer is on top of the target. (Screen 3) There are several sensors on top of the viewer. Each of those sensors indicates which of the attackers (only one) is within your shooting range and can be destroyed by you. If the sensors are off, none of the attackers will be within the shooting range. (Screen 4)
The battle begins! Remember that you can destroy only one attacker at any given time, so you will have to discover which one, if any, is the one within the shooting range. Remember not to waste the ammunition on the attackers that are beyond the shooting range. Call the experimenter if you have any doubts. Otherwise, click with the mouse to begin. GOOD LUCK!"

Participants confronted a situation in which they were free to give a response at any given time without penalties for giving the response in the absence of the stimulus, following a method that has consistently produced reliable discriminations in our laboratory (e.g., Gámez y Rosas, 2005, 2007; León et al., 2010a, b). Each trial was divided into the PreStimulus and Stimulus periods - for a graphical representation of the experimental setting see León et al. (2010b). During the Pre period, the tank and the plane were presented without the discriminative stimulus for $4 \mathrm{~s}$; responding during this period was not reinforced. During the 4-s Stimulus period, the tank and the plane were presented accompanied by the relevant discriminative stimuli, depending on the trial, and participants were free to perform the available responses. Giving the appropriate response for the present discriminative stimulus (i.e., clicking on the correct key when red sensor was on) led to destruction of the attacker (reinforcer) under a VI2-s reinforcement schedule in which the availability of reinforcement varied randomly between $1 \mathrm{~s}$ and $3 \mathrm{~s}$. Once the reinforcer was available, the trial ended only after the participant gave the correct response.

The experiment was conducted in two phases (see the experimental design in the first row of Table 1).

Discriminative training A screen with the sentence "Your detachment has been posted to... (name of the beach where the battle continued)" was presented for $2 \mathrm{~s}$ before starting training in each context. Participants received three training 
trials with each discriminative stimulus. X:R1-O1, R2- and $\mathrm{Z}: \mathrm{R} 1-, \mathrm{R} 2-$ trials were conducted in context A, and Y:R1-, R2- and J:R1-, R2- trials were conducted in context B. Trial order within each context was random. Half of the participants were first trained in context A and then trained in context B, and vice versa for the other half.

Context test All participants received a test trial in extinction with $\mathrm{X}$ and $\mathrm{Y}$ in each context. The order of presentation of the contexts was counterbalanced across participants.

\section{Dependent variable and statistical analyses}

Total mouse clicks on each target discriminative stimulus during Pre and Stimulus periods were recorded and transformed to responses per minute. Responding was evaluated by analysis of variance (ANOVA). The rejection criterion was set at $p$ $<.05$, and effect sizes were reported using partial eta-squared $\left(\eta_{\mathrm{p}}{ }^{2}\right)$. Moreover, $90 \%$ confidence intervals for the effect sizes were calculated and reported for each analysis.

\section{Results and discussion}

Discriminative training Rate of responding on the reinforced and non-reinforced response alternatives during the Pre $(\mathrm{N})$ and Stimulus (S) periods for each target (X and $\mathrm{Y}$ ) and nontarget $(\mathrm{Z}$ and $\mathrm{J}$ ) discriminative stimulus in the last trial of training is presented in the top section of Table 2. A 2 (Period, pre vs. stimulus) $\times 2$ (Target, target vs. non target $) \times$ 2 (Context, A vs. B) $\times 2$ (Response, R1 vs. R2) did not find a significant 4-way interaction, $F<1$. However, as differences were expected only in $\mathrm{R} 1$ and in target stimulus $\mathrm{X}$ with respect to both target stimulus $\mathrm{Y}$ and non-target stimulus $\mathrm{Z}$, planned comparisons focused in testing those differences. A 2 (Period) $\times 2$ (Context) ANOVA conducted with target stimuli $(\mathrm{X}$ in context $\mathrm{A}$ and $\mathrm{Y}$ in context $\mathrm{B}$ ) found a significant Period $\times$ Context interaction $F(1,23)=5.89, p<.05, \eta_{\mathrm{p}}{ }^{2}=.204$ [CI: $.01-.40]$. Subsequent analyses found that the simple effect of Period was significant for the reinforced stimulus X, $F(1,23)$ $=54.93, p<.001, \eta_{\mathrm{p}}{ }^{2}=.705$ [CI: .29-.74], but it was not significant for the non-reinforced stimulus $\mathrm{Y}, F(1,23)=3.99$, $p=.058$. So, participants learned to respond with $\mathrm{R} 1$ in the presence of $\mathrm{X}$ in context $\mathrm{A}$, and not in the presence of $\mathrm{Y}$ in context $B$. The same analysis conducted with the Non-Target stimuli ( $\mathrm{Z}$ in context $\mathrm{A}$ and $\mathrm{J}$ in context $\mathrm{B}$ ) found a significant main effect of Period, $F(1,23)=8.09, p<.01, \eta_{\mathrm{p}}{ }^{2}=.260$ [CI: $.04-46]$. No other main effect or interaction was significant, largest $F(1,23)=2.20, p=.151, \eta_{\mathrm{p}}{ }^{2}=.088$ [CI: .00-.28] for the main effect of Context, suggesting that, in general terms, there was a trend to respond more with $\mathrm{R} 1$ in the presence of the stimulus than in its absence. Finally, a 2 (Period, pre vs. stimulus) $\times 2$ (Target, $\mathrm{X}$ vs. Z) ANOVA found a significant
Period $\times$ Target interaction, $F=5.49, p<.05, \eta_{\mathrm{p}}{ }^{2}=.193$ [CI: $.01-.40]$ confirming the idea that responding on R1 was greater in X than in the non-reinforced stimuli, regardless of the context in which these stimuli were presented.Similar analyses conducted with R2 only found a significant main effect of Period $F(1,23)=5.05, p<.05, \eta_{\mathrm{p}}{ }^{2}=.180$ [CI: .01-.38]. No other main effect or interaction was significant, largest $F(1$, 23) $=2.70, p=.114, \eta_{\mathrm{p}}{ }^{2}=.105$ [CI: .00-.30] for the main effect of Context.

In summary, there was a general increase in responding in the presence of the stimuli, regardless of whether the response was reinforced or not, suggesting some degree of generalization. However, this increase was greater for the reinforced response (R1) in stimulus $\mathrm{X}$ than for the stimuli that were not reinforced, suggesting that participants have learned that $\mathrm{R} 1$ was reinforced in the presence of $\mathrm{X}$.

Context test Figure 1 presents mean responses per minute to the originally reinforced alternative (R1) in the presence of discriminative stimuli $\mathrm{X}$ and $\mathrm{Y}$, within the context in which they were trained (Same) and in the alternative context (Different) at the test phase of Experiment 1. A 2 (Context, A vs. B) $\times 2$ (Stimulus, $\mathrm{X}$ vs. Y) ANOVA found significant main effects of Context, $F(1,23)=12.10, p<.01, \eta_{\mathrm{p}}{ }^{2}=.345$ [CI: .03-.53], Stimulus, $F\left(1,23=11.98, p<.01, \eta_{\mathrm{p}}{ }^{2}=.342\right.$ [CI: .09-.52]. The Context $\times$ Stimulus interaction was significant as well, $F(1,23)=9.29, p<.01, \eta_{\mathrm{p}}{ }^{2}=.288$ [CI: .05-.48]. Subsequent analyses conducted to explore this interaction found that the simple effect of Context was significant for $\mathrm{X}$, $F(1,23)=20.77, p<.001, \eta_{\mathrm{p}}{ }^{2}=.475$ [CI: .20-.62], while it was not significant for $\mathrm{Y}, F<1$.

Mean responding during the Pre period was $16.25( \pm 5.91)$ and $13.12( \pm 5.44)$ responses per minute in the presence of stimulus $X$, and $7.5( \pm 2.85)$, and $14.37( \pm 6.22)$ responses per minute in the presence of stimulus $\mathrm{Y}$ in contexts Same and Different, respectively. A 2 (Context) $\times 2$ (Stimulus) ANOVA found no significant main effects or interaction, largest $F(1,15)=1.04, p=.323$.

Finally, responding on the non-reinforced alternative (R2) mirrored responding on the reinforced alternative, probably due to response competition: $8.12( \pm 3.72)$ and $34.37( \pm 7.02)$ responses per minute in the presence of stimulus $\mathrm{X}$, and 23.75 $( \pm 4.50)$ and $24.37( \pm 7.43)$ responses per minute in the presence of stimulus $Y$ in contexts Same and Different, respectively. A 2 (Context) $\times 2$ (Stimulus) ANOVA found a significant main effect of Context, $F(1,23)=4.83, p<.05, \eta_{\mathrm{p}}^{2}=.174$ [CI: .00-.37], and a significant Context $\times$ Stimulus interaction, $F(1,23)=7.44, p<.05, \eta_{\mathrm{p}}{ }^{2}=.245$ [CI: .03-.44]. Subsequent analysis conducted to explore the Context $\times$ Stimulus interaction found that the simple effect of Context was significant in stimulus $\mathrm{X}, F(1,23)=12.95, p<.01, \eta_{\mathrm{p}}{ }^{2}=.360$ [CI: .10-.54] but it was not significant in stimulus $\mathrm{Y}, F<1$. 
Table 2 Rate of responding during Pre-Training and Discriminative Training phases in Experiments 1, 2, 3, and 4

\begin{tabular}{|c|c|c|c|c|c|c|c|}
\hline \multirow{2}{*}{$\frac{\text { Experiment }}{1}$} & & & \multicolumn{3}{|l|}{ Pre-training } & \multicolumn{2}{|c|}{ Discriminative training (R1 vs. R2) } \\
\hline & & & & & & $\mathrm{X}$ & $\mathrm{Y}$ \\
\hline & $\mathrm{N}$ & & & & & $\begin{array}{l}26.87 \pm 7.33 \\
3.75 \pm 1.86\end{array}$ & $\begin{array}{l}30.62 \pm 7.63 \\
13.75 \pm 4.22\end{array}$ \\
\hline & $\mathrm{S}$ & & & & & $\begin{array}{l}90.00 \pm 8.02 \\
16.25 \pm 6.75\end{array}$ & $\begin{array}{l}52.5 \pm 8.94 \\
26.25 \pm 7.78\end{array}$ \\
\hline & & & & & & $\mathrm{Z}$ & $\mathrm{J}$ \\
\hline & $\mathrm{N}$ & & & & & $\begin{array}{l}26.87 \pm 6.57 \\
15.62 \pm 4.55\end{array}$ & $\begin{array}{l}24.37 \pm 7.04 \\
13.75 \pm 4.03\end{array}$ \\
\hline & $\mathrm{S}$ & & & & & $\begin{array}{l}52.50 \pm 8.84 \\
25.00 \pm 7.74\end{array}$ & $\begin{array}{l}33.75 \pm 8.53 \\
34.37 \pm 10.15\end{array}$ \\
\hline \multirow[t]{6}{*}{2} & & $\mathrm{R} 1$ & $\mathrm{R} 2$ & R3 & $\mathrm{R} 4$ & $\mathrm{X}$ & $\mathrm{Y}$ \\
\hline & $\mathrm{N}$ & $\begin{array}{l}100.31 \pm 8.63 \\
14.06 \pm 7.68\end{array}$ & $\begin{array}{l}106.87 \pm 8.96 \\
10.31 \pm 5.76\end{array}$ & $\begin{array}{l}98.44 \pm 11.93 \\
4.68 \pm 2.97\end{array}$ & $\begin{array}{l}90.93 \pm 8.81 \\
9.37 \pm 4.51\end{array}$ & $\begin{array}{l}7.50 \pm 3.06 \\
6.56 \pm 2.35\end{array}$ & $\begin{array}{l}17.81 \pm 6.87 \\
7.50 \pm 7.50\end{array}$ \\
\hline & $\mathrm{S}$ & & & & & $\begin{array}{l}97.50 \pm 8.87 \\
21.56 \pm 9.38\end{array}$ & $\begin{array}{l}49.68 \pm 11.10 \\
30.00 \pm 8.44\end{array}$ \\
\hline & & & & & & $\mathrm{Z}$ & $\mathrm{J}$ \\
\hline & $\mathrm{N}$ & & & & & $\begin{array}{l}3.75 \pm 1.67 \\
5.62 \pm 3.02\end{array}$ & $\begin{array}{l}8.43 \pm 2.36 \\
9.37 \pm 3.59\end{array}$ \\
\hline & $\mathrm{S}$ & & & & & $\begin{array}{l}52.5 \pm 13.34 \\
43.12 \pm 11.68\end{array}$ & $\begin{array}{l}57.18 \pm 13.29 \\
38.43 \pm 11.69\end{array}$ \\
\hline \multirow[t]{7}{*}{3} & & $\mathrm{X}(\mathrm{R} 3 / \mathrm{R} 4)$ & $\mathrm{Y}(\mathrm{R} 3 / \mathrm{R} 4)$ & & & $\mathrm{X}$ & $\mathrm{Y}$ \\
\hline & $\mathrm{N}$ & $\begin{array}{l}15.93 \pm 7.80 \\
3.75 \pm 1.67\end{array}$ & $\begin{array}{l}18.75 \pm 8.82 \\
8.43 \pm 4.53\end{array}$ & & & $\begin{array}{l}5.62 \pm 3.02 \\
3.75 \pm 2.16\end{array}$ & $\begin{array}{l}4.68 \pm 1.79 \\
4.68 \pm 1.79\end{array}$ \\
\hline & $\mathrm{S}$ & $\begin{array}{l}61.87 \pm 7.22 \\
25.31 \pm 6.23\end{array}$ & $\begin{array}{l}21.56 \pm 6.84 \\
31.87 \pm 10.23\end{array}$ & & & $\begin{array}{l}85.31 \pm 9.65 \\
20.62 \pm 8.86\end{array}$ & $\begin{array}{l}25.31 \pm 10.03 \\
34.68 \pm 11.43\end{array}$ \\
\hline & & & & & & $\mathrm{Z}$ & $\mathrm{J}$ \\
\hline & $\mathrm{N}$ & & & & & $\begin{array}{l}4.68 \pm 1.79 \\
1.87 \pm 1.28\end{array}$ & $\begin{array}{l}10.31 \pm 6.52 \\
1.87 \pm 1.28\end{array}$ \\
\hline & $\mathrm{S}$ & & & & & $\begin{array}{l}25.31 \pm 8.94 \\
35.62 \pm 9.57\end{array}$ & $\begin{array}{l}44.06 \pm 9.91 \\
25.31 \pm 7.95\end{array}$ \\
\hline & & & & & & $\mathrm{X}$ & $\mathrm{Y}$ \\
\hline \multirow[t]{5}{*}{4} & $\mathrm{~N}$ & & & & & $\begin{array}{l}8.43 \pm 2.35 \\
7.50 \pm 4.54\end{array}$ & $\begin{array}{l}4.68 \pm 2.25 \\
6.56 \pm 2.35\end{array}$ \\
\hline & $\mathrm{S}$ & & & & & $\begin{array}{l}65.62 \pm 8.75 \\
36.56 \pm 11.85\end{array}$ & $\begin{array}{l}18.75 \pm 7.56 \\
84.37 \pm 8.53\end{array}$ \\
\hline & & & & & & $\mathrm{Z}$ & $\mathrm{J}$ \\
\hline & $\mathrm{N}$ & & & & & $\begin{array}{l}16.87 \pm 5.78 \\
9.37 \pm 3.31\end{array}$ & $\begin{array}{l}3.75 \pm 2.16 \\
9.37 \pm 3.59\end{array}$ \\
\hline & $\mathrm{S}$ & & & & & $\begin{array}{l}29.06 \pm 6.34 \\
26.25 \pm 5.03\end{array}$ & $\begin{array}{l}26.25 \pm 7.04 \\
27.18 \pm 5.34\end{array}$ \\
\hline
\end{tabular}

Note: $S$ stimulus present; $N$ stimulus absent; $X, Y, Z$, and $J$ : Discriminative stimuli of different colors (red, navy blue, red blue or gray, counterbalanced). R1 and R2 in Experiment 1: Clicking on the plane or the tank, counterbalanced. R1, R2, R3, and R4 in Experiments 2 to 4: Clicking on different keys on the screen that were labeled as 1,2,3, or 4, counterbalanced. Data are reported as rate of responding per minute. Standard error of the mean is reported next to each rate. Rate of responding in the reinforced alternatives is presented in italics. During discriminative training, responding to R1 is reported in the top row and responding to $\mathrm{R} 2$ is reported in the bottom row within each cell

A deleterious effect of context change upon performance was found for the reinforced discriminative stimulus X, replicating the basic result reported by León et al. (2010b). A context-based difference on responding in the presence of $\mathrm{Y}$ in the opposite direction would be expected if the main source of the context-switch effect in this situation was an association between the context and the outcome, given that $Y$ was trained in a context where no reinforcement was presented, and tested in a context in which $X$ was reinforced (see Leon et al., 2011). This was not the case, as the context switch effect appears in X and not in Y. The asymmetric effect of switching the context between stimulus $\mathrm{X}$ and stimulus $\mathrm{Y}$ suggests that context- 


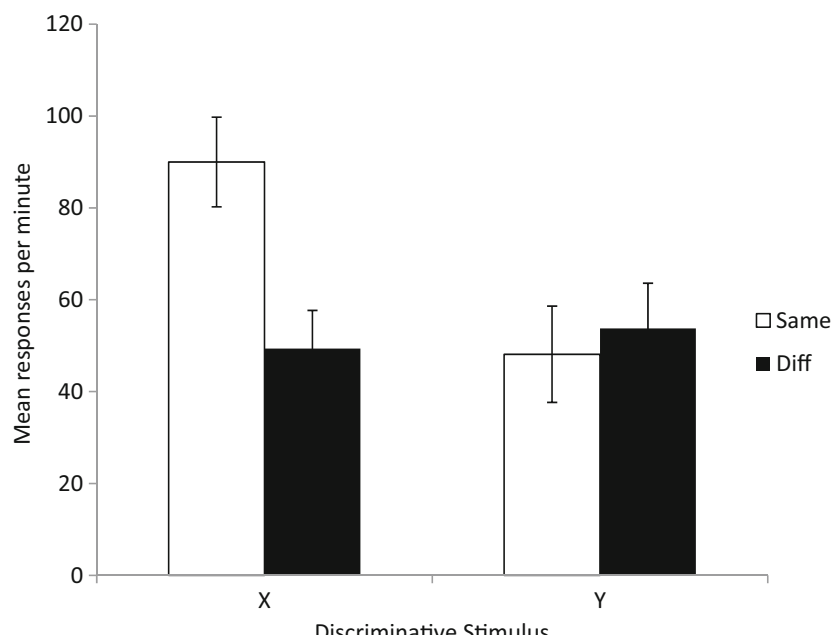

Fig. 1 Mean responses per minute in R1 in the presence of discriminative stimuli $\mathrm{X}$ (reinforced) and $\mathrm{Y}$ (no-reinforced) during the test conducted in the same context where they were trained (Same) or in the alternative context (Diff) at the test phase of Experiment 1. Error bars represent the standard error of the mean

outcome associations do not play a relevant role in the impairment of performance observed with the context-switch in this human instrumental task. This asymmetry poses a similar problem for a configural approach (e.g., Pearce, 1994). Assuming that training may have led to the formation of different context-discriminative stimulus configurations that would be associated with the presence or the absence of reinforcement, the loss of performance when part of the excitatory configuration is lost with the context change should be reversed as the same context change would attach part of the excitatory configuration to stimulus Y (see Glautier, 2004).

The asymmetric effect of switching contexts upon $\mathrm{X}$ and $\mathrm{Y}$ could be easily explained if contexts would play the role of occasion setters, so that context A sets the occasion for stimulus $\mathrm{X}$ to announce that responding on $\mathrm{R} 1$ is reinforced (e.g., Bouton \& Swartzentruber, 1986). However, claiming a modulation role for the contexts after such a short training as the one used here may not be parsimonious, as feature positive and feature negative training do not seem easy to establish (e.g., Bouton \& Nelson, 1998), even in humans (e.g., Baeyens, Hendricks, Crombez, \& Hermans, 1998; Declercq $\&$ De Houwer, 2011). The asymmetric effect of context change may also be explained in terms of the formation of an association between context $\mathrm{A}$ and discriminative stimulus $\mathrm{X}$, so that when $\mathrm{X}$ is presented outside context $\mathrm{A}$, responding is impaired. This result will not be expected with stimulus Y. As stimulus $\mathrm{Y}$ was never reinforced, changing the context should have no effects.

Given that this experiment was designed to match as much as possible the design used by León et al. (2011) in a predictive learning situation, it is tempting to conclude that the associations established in simple acquisition depend on the type of learning (predictive or instrumental). Alternatively, the type of learning could affect the association that is expressed in a given situation, rather than the association that is established. Human and nonhuman animals have been shown to establish different associations within the same situation (see for instance, Colwill \& Motzkin, 1994; Gámez \& Rosas, 2007). Contexts may enter into an association with all the other elements present in the situation, even though the underlying mechanism that finally enters into play may depend on factors such as the type of learning, the opportunity of responding, the conditions allowed by the experimental setting, or even the dependent variable selected by the experimenter. The goal of the following experiments was to explore whether the different associations involving the context may be detected within the basic experimental design used in Experiment 1. Experiment 2 explored the presence of an association between the context and the outcome; Experiment 3 explored the presence of context-stimulus associations; finally, Experiment 4 explored whether context-response associations are established within this design. Showing that contexts enter into different associations within the same situation would set the grounds for exploring the conditions in which those associations play a role as the underlying mechanism of context change in further research.

\section{Experiment 2}

The asymmetric effect of switching the context found in Experiment 1 cannot be explained in terms of direct associations between the context and the outcome (c.f., León et al., 2011). However, results of Experiment 1 do not mean that context-outcome associations fail to be established in the simple discriminative training paradigm. The goal of Experiment 2 was to explore whether this simple discrimination training leads to the formation of context-outcome associations. To analyze the presence of context-outcome associations we chose a variation of a transfer technique that has shown its usefulness to detect stimulus-outcome associations both in classical conditioning/predictive learning (e.g., Colwill \& Motzkin, 1994; Gámez et al., 2013; Paredes-Olay, Abad, Gámez, \& Rosas, 2002) and in human and nonhuman animal instrumental conditioning (e.g., Colwill \& Rescorla, 1988; Gámez \& Rosas, 2005, 2007; Rescorla, 1991, 1992). In a transfer procedure, the state of stimulus-outcome associations is evaluated through the transfer of the stimulus control from the trained stimulus to a response trained with the same outcome in the absence of the stimulus. Colwill and Rescorla (1988) used this transfer technique to evaluate the stimulusoutcome relationship in instrumental conditioning. They trained rats to perform an instrumental response to obtain sucrose in the presence of a discriminative stimulus, while reinforcing a different response with pellets in the presence of 
another discriminative stimulus. Rats were then trained with two new responses, one reinforced with sucrose and the other one reinforced with pellets. Finally, animals were tested in extinction in the presence of the two discriminative stimuli with the two responses that were never paired with them. Each discriminative stimulus specifically facilitated responding for the response alternative with which it shared the outcome, supporting the idea that the discriminative stimulus was associated with the outcome during discriminative training.

The design of Experiment 2 is presented in the second row of Table 1. Discriminative training was identical to the one used in Experiment 1, with the exception that clicking on the discriminative cues (the attackers) was changed by clicking on different keys of the screen labeled with numbers. This change allowed different responses to be followed by the same outcome. During Pre-training, participants were trained to perform four different responses associated with two different outcomes in the absence of contexts or discriminative stimuli: $\mathrm{R} 1$ and R3 were paired with $\mathrm{O} 1$, while R2 and R4 were paired with $\mathrm{O} 2$. A test of the association between the context and the outcome was conducted after discriminative training with R1 and R2. During the test, participants were allowed to perform R3 and R4 within each context (A and B) in the absence of discriminative stimuli. If an association between contexts and outcomes was established during discriminative training, responding to R3 should be greater than responding to R4, but only in context $\mathrm{A}$, given that context $\mathrm{A}$ was the only one in which the outcome was presented. In other words, we expected that the association between context $\mathrm{A}$ and $\mathrm{O} 1$ would boost responding in the response alternative that shared the outcome with the context (R3) with respect to the alternative outcome, or the alternative context.

\section{Method}

\section{Participants}

Sixteen undergraduates at the University of Jaén (14 women, two men; $\mathrm{M}_{\mathrm{age}}=18.75$ years, age range $=18-21$ years) participated in this experiment in exchange for course credit.

\section{Apparatus and stimuli}

Apparatus, stimuli, and the rest of experimental settings were the same as those used in Experiment 1, except that instrumental responses involved clicking on one of four keys labeled as 1, 2, 3, or 4 and located at the bottom area of the screen. Keys 1 and 2 were counterbalanced with keys 3 and 4 as $R 1 / R 2$ and $R 3 / R 4$, so that $R 1$ and $R 3$ could be any of the even keys, and R2 and R4 could be any of the pair keys.
Destruction of the tank and the plane was counterbalanced as outcomes 1 and 2 across participants.

\section{Procedure}

In this experiment we used the same instructions set as in Experiment 1, except where noted. The experiment was conducted in three phases (see second row of Table 1).

Pre-training During this phase, either the tank or the plane was presented alone, in the absence of contexts or discriminative stimuli. All participants received six trials with each combination R1-O1, R2-O2, R3-O1, and R4-O2. Half of the participants were trained first with R1 and R2, and then with R3 and R4, while the reverse was true for the other half. Participants were free to use the two available responses in each phase of pre-training, but only one of them resulted in an outcome. The change from one set of responses to the other was signaled by an instruction indicating to the participant that the current weapons were failing and indicating which new response (weapon) should be used afterwards.

Discriminative training Training was identical to Experiment 1.

Association test The test began with the following instructions:

"(Screen 1) Attention, your enemies are getting too close! From now on you will not see colored sensors indicating when your enemies are within the shooting range because THEY ARE ALWAYS WITHIN THE SHOOTING RANGE! Thus, you should shoot as soon as you see the enemies to be able to destroy them. Besides, the enemies are using a protective shield that makes them more resistant to your attack. So, you should intensify your attack and focus on the enemy that you think it is more vulnerable. (Screen 2) Finally, we should advise you that your current weapons are failing. During this period we have repaired keys 1 and 2 so that from now on you should use only those keys to destroy tanks and planes with efficiency. GO!"

One 4-s test trial with each context, A and B was conducted. Within each context, the tank and the plane were presented at the same time, but only the responses that were not used during discriminative training, $\mathrm{R} 3$ and $\mathrm{R} 4$, were available to participants. 


\section{Results and discussion}

Pre-training Rate of responding on the reinforced and nonreinforced response alternatives on the last training trial of this phase are presented in the second section of Table 2. A 4 (Response) $\times 2$ (Reinforcement) ANOVA only found a significant main effect of Reinforcement, $F(1,15)=106.23, p<$ $.001, \eta_{\mathrm{p}}{ }^{2}=.876[\mathrm{CI}: .73, .91]$.

Discriminative training Rate of responding on the reinforced and non-reinforced response alternatives during the Pre $(\mathrm{N})$ and Stimulus (S) periods for each target (X and $\mathrm{Y}$ ) and nontarget $(\mathrm{Z}$ and $\mathrm{J}$ ) discriminative stimulus at the end of discriminative training is presented in the second section of Table 2. A 2 (Period, pre vs. stimulus $) \times 2$ (Target, target vs. non-target $) \times$ 2 (Context, A vs. B) $\times 2$ (response, R1 vs. R2) ANOVA found a significant 4-way interaction, $F(1,15)=5.63, p<.05, \eta_{\mathrm{p}}{ }^{2}=$ .273 [CI: .01-.50]. Planned comparisons focused on testing the differences between $\mathrm{X}$ and the rest of discriminative stimuli, as discrimination should be detected as a greater increase on the reinforced alternative $\mathrm{R} 1$ in the reinforced stimulus $\mathrm{X}$ than in the alternative stimuli and response. A 2 (Period) $\times 2$ (Context) ANOVA conducted with target stimuli ( $\mathrm{X}$ in context $\mathrm{A}$ and $\mathrm{Y}$ in context $\mathrm{B}$ ) found a significant Period $\times$ Context interaction $F(1,15)=44.08, p<.001, \eta_{\mathrm{p}}{ }^{2}=.746$ [CI: .48-.83]. Subsequent analyses found that the simple effect of Period was significant in both, the reinforced stimulus $\mathrm{X}, F(1$, $15)=127.06, p<.001, \eta_{\mathrm{p}}{ }^{2}=.894$ [CI: .76-.93], and the nonreinforced stimulus $\mathrm{Y}, F(1,15)=10.06, p<.01, \eta_{\mathrm{p}}{ }^{2}=.401$ [CI: .08-.59]. That is, a difference between Pre and Stimulus periods was found in both target stimuli, the one reinforced $(\mathrm{X})$ and the one non-reinforced $(\mathrm{Y})$, suggesting some degree of generalization across discriminative stimuli that was also found in Experiment 1. However, the simple effect of Context was significant only in the Stimulus period, $F(1,15)=20.94$, $p<.001, \eta_{\mathrm{p}}{ }^{2}=.583$ [CI: .25-.72], indicating that responding during stimulus $\mathrm{X}$ was higher than responding during stimulus $\mathrm{Y}$, the expected discrimination result.The same analysis conducted with the non-target stimuli ( $\mathrm{Z}$ in context $\mathrm{A}$ and $\mathrm{J}$ in context $\mathrm{B}$ ) found a significant main effect of Period, $F(1,15)=$ $16.68, p<.001, \eta_{\mathrm{p}}^{2}=.526$ [CI:.18-.68]. Neither the other main effect nor the interaction were significant, $F s<1$, suggesting that, in general terms, there is a trend to respond more with R1 in the presence of the stimulus than in its absence.

Similar analyses conducted with R2 did not find any significant main effect or interaction, largest $F(1,15)=3.61, p=$ $.77, \eta_{\mathrm{p}}{ }^{2}=.194$ [CI: .00-.43] for the main effect of Period. In summary, there seems to be a general increase in responding in the reinforced alternative $\mathrm{R} 1$ in the presence of the stimuli, suggesting some degree of generalization across stimuli. However, this increase is greater in stimulus $\mathrm{X}$ than in nonreinforced stimuli, showing that participants have learned that $\mathrm{R} 1$ was reinforced in the presence of $\mathrm{X}$.
Incidentally, note that the rate of responding in the periods of non-reinforcement was lower in Experiment 2 (compare discriminative training in the first and second sections of Table 2). Most likely, this was due to the changes in the instrumental response between Experiment 1 (clicking directly on the attackers) and Experiment 2 (clicking in different response keys on the screen).

Association test Figure 2 shows mean responses per minute in R3 and R4 alternatives in the presence of contexts A and B. Responding in R3 was higher than responding in R4, but only in Context A, the context that shared the outcome with R3. A 2 (Context) $\times 2$ (Response) ANOVA found a significant main effect of Response, $F(1,15)=19.59, p<.001, \eta_{\mathrm{p}}{ }^{2}=.566$ [CI: .23-.71] and, most relevant for the goal of this study, a Context $\times$ Response significant interaction, $F(1,15)=5.42$, $p<.05, \eta_{\mathrm{p}}{ }^{2}=.266$ [CI: .01-.49]. Subsequent analyses conducted to explore this interaction found that the simple effect of Response was significant only in context $\mathrm{A}, F(1,15)=$ 26.00, $p<.001, \eta_{\mathrm{p}}^{2}=.624$ [CI: .31-.75], but it was not significant in context $\mathrm{B}, F(1,15)=1.35, p=.264$.

That is, only the context in which $\mathrm{O} 1$ was presented during discriminative training facilitated responding to the response alternative that was originally paired with the same outcome. In other words, Context A transferred its control to the response with which it shared the outcome. These results suggest that Context A was associated with $\mathrm{O} 1$ within the same discriminative training situation that was used in Experiment 1. The results obtained in Experiment 2 show that during short training in an instrumental discrimination task participants seem to associate the context with the outcome, even though the role of that association on

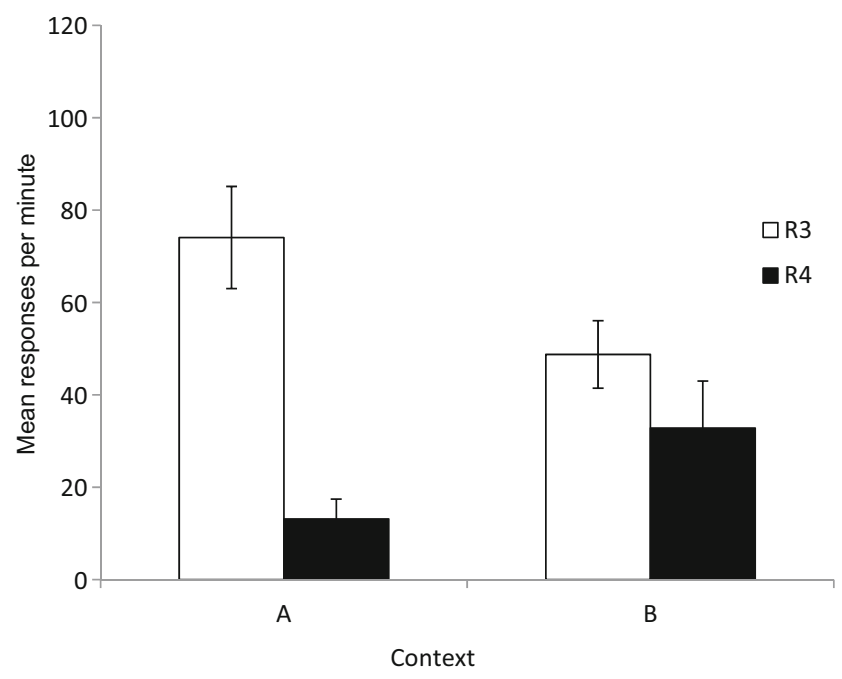

Fig. 2 Mean responses per minute in the reinforced response alternative that shared the outcome with context A during the discriminative training phase (R3), and in the alternative response (R4) in Experiment 2. Error bars represent the standard error of the mean 
controlling behavior may have gone unnoticed in Experiment 1. This conclusion should be taken with caution though, as the coincidence on the outcomes of R1 and R3, and R2 and R4 in Phase 1 may have encouraged generalization across responses. The transfer effect at testing may not depend on the context-outcome association, but on the association between context A and R1 that would be generalized to R3 more than to R4. However, as Gámez and Rosas (2007) noted, this interpretation requires the assumption of additional associations between responses mediated by the stimulus-attacker. The R1-O1 binary associations are not expected to be strong since $\mathrm{R} 1$ is not reinforced in half of the trials in context $\mathrm{A}$, and in $3 / 4$ of the trials overall. Although this design cannot discard this alternative interpretation, it certainly seems less parsimonious than the simpler interpretation in terms of context-outcome associations analogous to the one usually given in the literature to this type of result (e.g., Colwill \& Rescorla, 1988; Gámez \& Rosas, 2005, 2007).

\section{Experiment 3}

Experiment 2 uncovered the presence of an association between the context and the outcome after short training that was not evident with a standard test of context-switch effects. The goal of Experiment 3 was to explore whether an association between the context and the discriminative stimulus was also established within the same situation. Discriminative training was preceded by a phase in which two distinct responses (R3 and R4) were trained in the presence of two discriminative stimuli (X and $\mathrm{Y}$ ) within a white background (see third row in Table 1). Responding on R3 was reinforced in the presence of stimulus X, while no response was reinforced in the presence of stimulus $Y$. Stimulus $Y$ was included so that participants were forced to use the discriminative stimulus as part of the discrimination, instead of simply learning that responding on R3 was followed by reinforcement in the presence of any stimulus. Discriminative training was identical to that conducted in Experiments 1 and 2. At testing, stimulus $\mathrm{X}$ was presented within contexts A and B. During the final test, participants had to confront two new stimuli (attackers), using responses originally trained with $\mathrm{X}$ and $\mathrm{Y}$ (R3 and R4). Using two new attackers ensured that any differences on responding at testing could not be explained by the association between the context and the outcome. If participants established an association between Context $\mathrm{A}$ and stimulus $\mathrm{X}$ during discriminative training, this association might be expected to enhance responding to $X$ only in Context $\mathrm{A}$, but not in Context $\mathrm{B}$, given that $\mathrm{X}$ was not presented in context B before.

\section{Method}

\section{Participants}

Sixteen undergraduates at the University of Jaén $\left(\mathrm{M}_{\mathrm{age}}=19.1\right.$ years, age range 18-23 years) participated in this experiment for course credit. All of them were women.

\section{Apparatus and stimuli}

Apparatus, stimuli, and the rest of experimental settings were identical to the ones used in Experiment 2, except that two new attackers, a ship and a helicopter, were included in the test phase. They appeared on areas of the screen where no attackers were presented before. The ship was presented in the sea, at the bottom right area of the context, and the helicopter was presented on the sky, at the top left area of the context.

\section{Procedure}

Instructions in this experiment were identical to the ones used in the previous experiments, except where noted. The experiment was conducted in three phases (see the third row of Table 1).

Pre-training Six trials with each combination X:R3-O1, R4-, and Y:R3-, R4- were presented randomly intermixed. Each trial included a Pre and a Stimulus period. During the stimulus period, using R3 in the presence of $\mathrm{X}$ was reinforced, while no response was reinforced in the presence of $\mathrm{Y}$.

Discriminative training This phase was identical to the one described in Experiment 1.

Association test The test began with the following instructions:

"Attention! You have destroyed tanks and planes, but new enemies are approaching. For this battle you should use the weapons you used in the initial training, that is, keys 1 and 2 (or 3 and 4, depending on the counterbalancing). Do not forget to take the sensors into account to know which enemy may be destroyed at any given time. Victory is close!"

A single test trial with discriminative stimulus $\mathrm{X}$ was conducted within each context (A and B). In each trial two new enemies were presented (ship and helicopter). During the Preperiod the enemies were there by themselves, while during the Stimulus period, the stimulus in which presence response R3 had been previously reinforced was presented (stimulus $\mathrm{X}$, which also was a discriminative stimulus for the R1-O1 relationship during discriminative training). 


\section{Results and discussion}

Pre-training Mean responses per minute on the reinforced and non-reinforced response alternatives during the Pre $(\mathrm{N})$ and Stimulus (S) periods in the presence of discriminative stimuli $\mathrm{X}$ and $\mathrm{Y}$ at the end of pre-training are presented in the third section of Table 2 . A 2 (Period) $\times 2$ (Stimulus) $\times 2$ (Response) ANOVA found significant main effects of Period, $F(1,15)=28.03, p<.001, \eta_{\mathrm{p}}{ }^{2}=.651$ [CI: .34-.77], and Response, $F(1,15)=7.94, p<.05, \eta_{\mathrm{p}}{ }^{2}=.346$ [CI: .05-.56]. Period $\times$ Stimulus, $F(1,15)=16.53, p<.001, \eta_{\mathrm{p}}{ }^{2}=.524$ [CI: $.19-.68]$, and Stimulus $\times$ Response, $F(1,15)=5.09, p<.05$, $\eta_{\mathrm{p}}{ }^{2}=.253$ [CI: .01-.48], interactions were significant as well. Most important, the 3-way Period $\times$ Stimulus $\times$ Response interaction was significant, $F(1,15)=5.03, p<.05, \eta_{\mathrm{p}}^{2}=$ .251 [CI: .01-.48]. Subsequent analyses conducted to explore the 3-way interaction found that the Period $\times$ Stimulus interaction was significant only with the reinforced alternative (R3), $F(1,15)=17.73, p<.001, \eta_{\mathrm{p}}{ }^{2}=.542$ [CI: .20-.69], but it was not significant in the non-reinforced alternative (R3), $F<1$. Subsequent analyses conducted to explore the Period $\times$ Stimulus interaction with R3 found that the simple effect of Period was significant in Stimulus $\mathrm{X}, F(1,15)=$ $14.53, p<.01, \eta_{\mathrm{p}}{ }^{2}=.492$ [CI: .15-.66], but it was not significant in Stimulus $\mathrm{Y}, F<1$. So, participants learned to use R3 for destroying $\mathrm{O} 1$ only in the presence of $\mathrm{X}$ during pretraining.

Discriminative training The rates of responding on the reinforced and non-reinforced response alternatives during the Pre $(\mathrm{N})$ and Stimulus (S) periods for each target (X and $\mathrm{Y}$ ) and non-target $(Z$ and $J)$ discriminative stimulus at the end of training are presented in the third section of Table 2. A 2 (Period, pre vs. stimulus) $\times 2$ (Target, target vs. non-target $) \times$ 2 (Context, A vs. B) $\times 2$ (Response, R1 vs. R2) ANOVA found a significant 4-way interaction, $F(1,15)=6.57, p<.05, \eta_{\mathrm{p}}{ }^{2}=$ .304 [CI: .03-.53]. Planned comparisons focused on testing the differences between $\mathrm{X}$ in the other stimuli: Discrimination should be shown as differential responding to $\mathrm{X}$ than to the rest of stimuli but only in R1. A 2 (Period) $\times 2$ (Context) ANOVA conducted with target stimuli (X in context $\mathrm{A}$ and $\mathrm{Y}$ in context $\mathrm{B}$ ) found a significant Period $\times$ Context interaction $F(1,15)=18.34, p<.01, \eta_{\mathrm{p}}^{2}=.550$ [CI: .21-.70]. Subsequent analyses found that the simple effect of Period was significant for the reinforced stimulus $\mathrm{X}, F(1,15)=$ $54.87, p<.001, \eta_{\mathrm{p}}{ }^{2}=.785$ [CI: .55-.85], but it fell just short of significance for the non-reinforced target stimulus $\mathrm{Y}, F(1$, 15) $=4.21, p=.058, \eta_{\mathrm{p}}{ }^{2}=.219$ [CI: .00-.45]. That is, a difference between Pre and Stimulus periods was found in the reinforced target stimulus, though differences found in the non-reinforced target stimulus suggests some degree of generalization across discriminative stimuli that was already found in previous experiments of this series. The simple effect of Context was significant only in the Context period, $F(1,15)$ $=19.74, p<.001, \eta_{\mathrm{p}}{ }^{2}=.569$ [CI: .23-.71]. The same analysis conducted with the non-target stimuli $(\mathrm{Z}$ in context $\mathrm{A}$ and $\mathrm{J}$ in context B) only found a significant main effect of Period, $F(1$, $15)=11.87, p<0.01, \eta_{\mathrm{p}}{ }^{2}=.442$ [CI: .11-.62]. No other main effect or interaction were significant, largest $F(1,15)=2.56, p$ $=.13, \eta_{\mathrm{p}}{ }^{2}=.146$ [CI: .00-.38] for the Period $\times$ Context interaction. In general terms, there was a trend to respond more with $\mathrm{R} 1$ in the presence of the stimulus than in its absence, but responding was greater in the presence of the reinforced stimulus $\mathrm{X}$ than in the other stimuli, the expected discrimination result.Similar analyses conducted with R2 only found a significant main effect Period, $F(1,15)=13.97, p<0.01, \eta_{\mathrm{p}}{ }^{2}=$ .482 [CI: .14-.65]. No other main effect or interaction was significant, $F_{S}<1$.

In summary, there was a general increase in responding with the presence of the stimuli, suggesting some degree of generalization across stimuli and responses. However, this increase was clearly greater with R1 to stimulus X than with the non-reinforced stimuli, suggesting that participants have learned that R1 was reinforced in the presence of X.

Association test Figure 3 captures mean responding per minute in the reinforced and non-reinforced response alternatives (R3 and R4, respectively) during the Pre-period and in the presence of the discriminative stimulus $\mathrm{X}$ during the test conducted in contexts A and B in Experiment 3. Potential outcomes (destruction of a ship or a helicopter) were new, so that

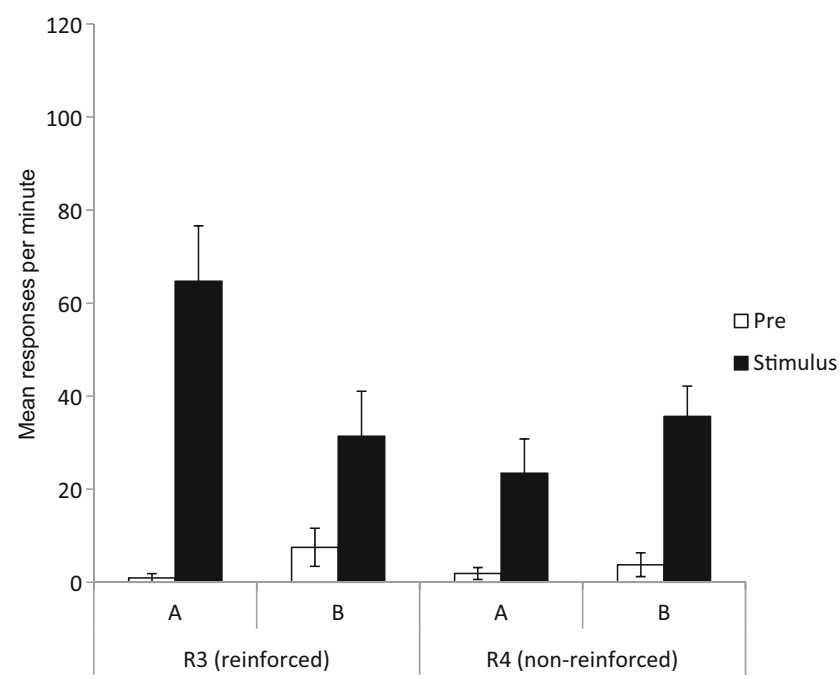

Fig. 3 Mean responses per minute in the reinforced and non-reinforced response alternatives (R3 and R4, respectively) during the Pre-period and in the presence of the discriminative stimulus $\mathrm{X}$ during the test conducted in contexts A and B in Experiment 3. Potential outcomes (destruction of a ship or a helicopter) were new, so that they were not available before to participants.R3 was reinforced with destruction of the planes and the tanks (counterbalanced) in the presence of $\mathrm{X}$ within a white context during the Pre-Training Phase. Error bars represent the standard error of the mean 
they were not available to participants before: Remember that $\mathrm{R} 3$ had been reinforced with the destruction of planes or tanks (counterbalanced) in the presence of $\mathrm{X}$ within a white context during the Pre-Training phase. A 2 (Response, R3 vs. R4) $\times 2$ (Period, pre vs. stimulus) $\times 2$ (Context, A vs. B) ANOVA found a 3-way interaction that fell just short of significance $F(1,15)=5.035, p=.051, \eta_{\mathrm{p}}{ }^{2}=.231$ [CI: .00-.37]. Subsequent planned comparisons were conducted with R3 and R4. A 2 (Period) $\times 2$ (Context) ANOVA conducted with the previously reinforced response (R3) found a significant main effect of Period, $F(1,15)=26.07, p<.001, \eta_{\mathrm{p}}{ }^{2}=.635$ [CI: .31-.75]. The Period $\times$ Context interaction was significant, $F(1,15)=6.78, p<.05, \eta_{\mathrm{p}}{ }^{2}=.311$ [CI: .03-.53]. The analyses conducted to explore this interaction found that the simple effect of Context was only significant during the stimulus, $F(1,15)=5.36, p<.05, \eta_{\mathrm{p}}{ }^{2}=.263[.01-.49]$. However, the simple effect of Period was significant both, Context A, $F(1,15)=27.97, p<.001, \eta_{\mathrm{p}}{ }^{2}=.651$ [CI: .34-.77], and Context B, $F(1,15)=5.04, p<.05, \eta_{\mathrm{p}}{ }^{2}=.251$ [CI: .00-.48].

Finally, responding on the non-reinforced alternative (R4) was $1.87( \pm 1.25)$ and $3.75( \pm 2.56)$ during Pre-period and $23.43( \pm 7.36)$ and $35.62( \pm 6.54)$ during the Stimulus-period in contexts $\mathrm{A}$ and $\mathrm{B}$, respectively. A 2 (Period) $\times 2$ (Context) ANOVA only found a significant main effect of Period, $F(1$, $15)=31.10, p<.001, \eta_{\mathrm{p}}{ }^{2}=.675$ [CI: .37-.78]. The main effect of Context and the Period $\times$ Context interaction were not significant, largest $F(1,15)=2.13, p=.165, \eta_{\mathrm{p}}{ }^{2}=.124$. These results show that responding on the non-reinforced alternative R4 in the presence of $\mathrm{X}$ did not differ across contexts, while responding on the reinforced alternative R3 did.

The rate of responding in the response alternative that was originally reinforced in the presence of $\mathrm{X}$ was greater in Context A than in Context B, even when the potentially available outcomes (attackers potentially destructible) were different during the test phase than the ones originally trained. The test was conducted in a situation in which responding should be mainly driven by the associations between discriminative stimulus $\mathrm{X}$ and the instrumental response originally trained with it, R3. Accordingly, participants were expected to choose R3, regardless of the context in which they were tested. However, if context A was associated with discriminative stimulus X during discriminative training, participants would chose R3 to a greater extent in the presence of context $A$ than in the presence of context B, as in fact happened. Remember that R3 was never associated with context A, and neither R3 nor context A was previously associated with the outcome available at testing. The explanation for $\mathrm{R} 3$ being chosen more often in context $\mathrm{A}$ than in context $\mathrm{B}$, even though the response is given in both contexts, seems to be that context A was associated with $\mathrm{X}$, favoring responding to any response alternative associated with it.

This conclusion could be modified if it was assumed that there was generalization across outcomes between training and testing. If that were the case, R3 would be more likely to be elicited than R4, since R3 was the only one previously rewarded. However, responding to R3 was only given when the discriminative stimulus $\mathrm{X}$ was present, and it was significantly higher in context A than in context B (something that did not happen with the unreinforced response R4). These results suggest that it is the combination of context and the stimulus that elicits responding; a result that fits the idea that context-stimulus associations were developed in this experiment.

As was the case with the context-outcome association uncovered by the design of Experiment 2, the association between the context and the stimulus is also established during discriminative training, suggesting that contexts may enter into different associations simultaneously.

\section{Experiment 4}

Experiments 2 and 3 have shown that during a short discrimination training that allows for the observation of a contextswitch effect upon performance, participants learned relationships between the context and the outcome, and between the context and the stimulus, regardless of whether those associations play a role in the context switch-effect that was detected in Experiment 1. The goal of Experiment 4 was to extend the exploration of the associations involving context in human discriminative training to the potential relationship between the context and the instrumental response.

The design of Experiment 4 is presented in the bottom row of Table 1. In this case, the discriminative training phase was closer to the one used by León et al. (2010b), as both contexts were associated with the outcome. León et al. (2010b) used two outcomes and R1 and R2 were reinforced in both contexts. In the present experiment only one outcome (O1) was used, and R1 and R2 were reinforced only in one of the contexts ( $\mathrm{A}$ and $\mathrm{B}$, respectively), so that the contexts would be differentially associated with a single response.

Given that the discriminative training was different from the one used in Experiments 1-3, the effect of switching the context was also evaluated here to ensure that the changes in the design did not eliminate the context-switch effect. This Context test was identical to the one conducted in Experiment 1, evaluating responding to stimuli $\mathrm{X}$ and $\mathrm{Y}$ in extinction in the same context in which they were trained, and in the alternative context. The context-switch effect should manifest as a greater rate of responding in context same than in context different in both, stimulus $\mathrm{X}$ and stimulus Y. Note that the potential effect of context-switch in this experiment would not be explained by context-outcome associations given that the outcome is equally present in both contexts.

Finally, the association between the context and the response was evaluated in the association test. During this test, 
participants had the opportunity to perform either R1 or R2 in contexts $\mathrm{A}$ and $\mathrm{B}$ in the absence of discriminative stimuli, and in the presence of a new stimulus (attacker), so that the trained outcomes would not be prompted. Under these conditions, any association between the context and the response should be reflected by a greater responding in $\mathrm{R} 1$ than in $\mathrm{R} 2$ in the presence of Context $\mathrm{A}$, and greater responding in $\mathrm{R} 2$ than in $\mathrm{R} 1$ in the presence of Context B.

\section{Method}

\section{Participants}

Sixteen undergraduate students at the University of Jaén (14 women, two men; $\mathrm{M}_{\text {age }}=20.10$ years, age range $18-31$ years) participated in the experiment in exchange of course credit.

\section{Apparatus and stimuli}

Instrumental responses were clicking in one of two keys labeled as 1 or 2 and located at the bottom area of the bunker. The rest of apparatus, stimuli and experimental settings were the same as those used in Experiments 2 and 3.

\section{Procedure}

Procedure was identical to the one used in Experiment 3, except where noted. The experiment was conducted in three phases (see bottom row of Table 1). Only one attacker at a time was presented throughout the experiment. The order in which context and association tests were conducted was counterbalanced across participants.

Discriminative training Training was identical to that conducted in the previous experiments, with the exception that in this occasion R2 was reinforced in the presence of $\mathrm{Y}$ in Context B, so that outcome $\mathrm{O} 1$ was presented in both contexts.

Context test This test was identical to the one conducted in Experiment 1 with the exception that only one of the attackers was present (a plane for a half of participants and a tank for the other half). The test started with the following instructions:

"Good work! Air attack continues (or land attack, depending on the counterbalancing). Sensors are still working. Keep using keys 1 and 2 to destroy your enemies."

Association test The test started with the following instructions:
"Attention! Enemy troops now attack by air (or by land, depending on the counterbalancing). They are so close that there will not be sensors to know when they are reachable, because they are always reachable! Keep using keys 1 and 2 to destroy your enemies. Good luck!"

A new attacker was presented in each context with no discriminative stimuli. For a given participant trained with the tank, the new attacker was a plane, and vice versa.

\section{Results and discussion}

Discriminative training The rates of responding on the reinforced and non-reinforced response alternatives during the Pre (N) and Stimulus (S) periods for each target (X and Y) and nontarget ( $\mathrm{Z}$ and $\mathrm{J}$ ) discriminative stimulus in the last training trial are presented at the bottom section of Table 2. A 2 (Period, pre vs. stimulus) $\times 2$ (Target, target vs. non target) $\times 2$ (Context, A vs. B) $\times 2$ (Response, R1 vs. R2) ANOVA found a significant 4-way interaction, $F(1,15)=15.38, p<.01, \eta_{\mathrm{p}}{ }^{2}=$ .506 [CI: .16-.67]. Subsequent analyses conducted to explore the 4-way interaction found that the 3 -way Target $\times$ Context $\times$ Response interaction was significant for the Stimulus Period, $F(1,15)=13.30, p<.01, \eta_{\mathrm{p}}{ }^{2}=.470$ [CI: .13-.64], but it was not significant during the Pre Period, $F(1,15)=1.58, p=.227$, $\eta_{\mathrm{p}}{ }^{2}=.096$ [CI: .00-.33]. The Context $\times$ Response interaction was significant in the Target stimuli, $F(1,15)=16.44, p<.01$, $\eta_{\mathrm{p}}{ }^{2}=.523$ [CI: .18-.68], but it was not significant in the nonTarget stimuli, $F<1$. The simple effect of Response was significant at each level of context, that is, in stimulus $\mathrm{X}, F(1,15)$ $=6.35, p<.05, \eta_{\mathrm{p}}{ }^{2}=.298$ [CI: .02-.52], and in stimulus $\mathrm{Y}$, $F(1,15)=26.43, p<.001, \eta_{\mathrm{p}}{ }^{2}=.638$ [CI: .32-.76]. Descriptive statistics show responding for $\mathrm{R} 1$ was greater than responding for $\mathrm{R} 2$ in stimulus $\mathrm{X}$, and vice versa in stimulus $\mathrm{Y}$ (see Table 2). By the end of the discriminative training phase participants had learned to use $\mathrm{R} 1$ in the presence of $\mathrm{X}$ in Context $\mathrm{A}$ and $\mathrm{R} 2$ in the presence of $\mathrm{Y}$ in Context $\mathrm{B}$.

Context test Figure 4 presents mean responses per minute in the response alternative that was originally reinforced in the presence of discriminative stimuli X (R1) and Y (R2) during the test conducted in the same context where they were trained (Same) and in the alternative context (Different). A 2 (Context) $\times 2$ (Stimulus) ANOVA only found a significant main effect of Context, $F(1,15)=6.68, p<.05, \eta_{\mathrm{p}}{ }^{2}=.308$ [CI: .03-.52]. Planned comparisons showed that the simple effect of Context was significant in both discriminative stimuli, $\mathrm{X}, F(1,15)=4.73, p<.05, \eta_{\mathrm{p}}{ }^{2}=.240$ [CI: .00-.47], and $\mathrm{Y}, F(1,15)=7.16, p<.05, \eta_{\mathrm{p}}{ }^{2}=.323$ [CI: .04-.54]. No differences were found during the Pre period, $F(1,15)=$ $1.34, p=.264$.Finally, responding on the non-reinforced 


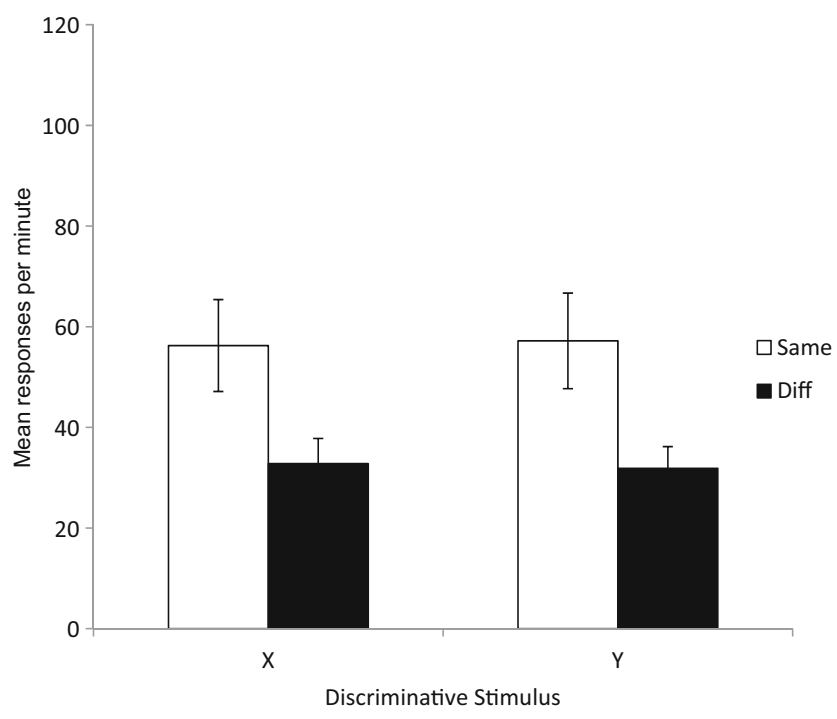

Fig. 4 Mean responses per minute in the response alternatives previously reinforced in the presence of discriminative stimuli X (R1) and Y (R2) during the test conducted in the same context where they were trained (Same) or in the alternative context (Diff) at the Context Test phase of Experiment 4. Error bars represent the standard error of the mean

alternative mirrored responding on the reinforced alternative: $32.81( \pm 9.40)$, and $45.93( \pm 9.02)$ responses per minute in the presence of stimulus $X(\mathrm{R} 2)$, and $25.31( \pm 5.60)$, and 43.12 $( \pm 8.08)$ responses per minute in the presence of stimulus $\mathrm{Y}$ (R1) in contexts Same and Different, respectively. A 2 (Context) $\times 2$ (Stimulus) ANOVA only found a significant main effect of Context, $F(1,15)=16.75, p<.001, \eta_{\mathrm{p}}{ }^{2}=$ .528 [CI: .19-.68]. In agreement with the results reported by León et al. (2010a), the context switch had a deleterious effect on performance in a situation in which the experience with the outcome was identical in both contexts, and thus could not be explained by context-outcome associations.

Association test Figure 5 presents mean responses per minute in the presence of contexts $\mathrm{A}$ and $\mathrm{B}$ in the response alternatives R1 and R2 (R1 had been reinforced in context A, and R2 had been previously reinforced in context B). A 2 (Context, A vs. B) $\times 2$ (Response, R1 vs. R2) ANOVA only found a significant Context $\times$ Response interaction, $F(1,15)=10.07, p<$ $.01, \eta_{\mathrm{p}}{ }^{2}=.402$ [CI: .08-.60]. Subsequent analyses conducted to explore this interaction found that the simple effect of Response was significant in both contexts, A, $F(1,15)=$ $6.10, p<.05, \eta_{\mathrm{p}}{ }^{2}=.289$ [CI: .02-.41] and $\mathrm{B}, F(1,15)=$ 9.38, $p=.01, \eta_{\mathrm{p}}{ }^{2}=.385$ [CI: .60-.48], though descriptive analyses show that the direction of the differences were opposite in contexts A and B.

Note that at the Association test a new stimulus (attacker) was used. That is, a new potential outcome that was not previously associated to any of the contexts or the responses was presented at testing. As the Contexts A and B and Responses R1 and R2 were equally associated with the outcome, the

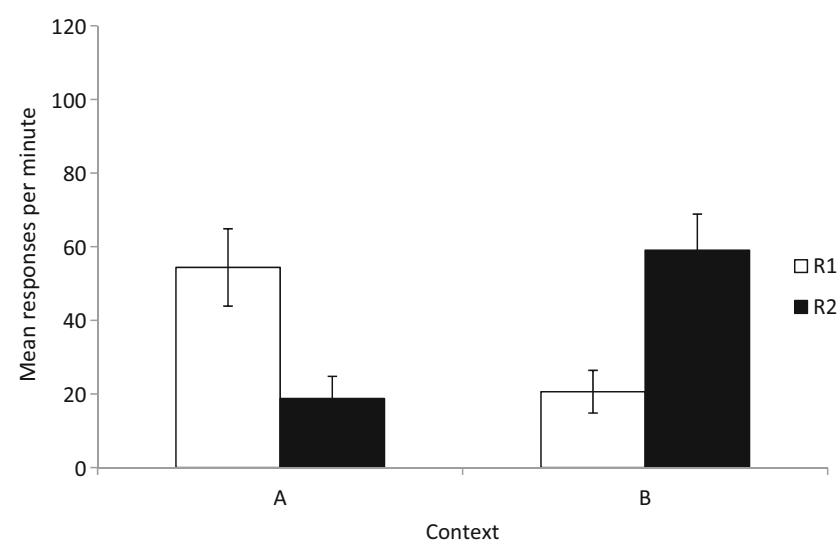

Fig. 5 Mean responses per minute in the presence of contexts A and B in the response alternative originally reinforced $(\mathrm{R} 1$ in context $\mathrm{A}$ and $\mathrm{R} 2$ in context $\mathrm{B}$ ), and in the response alternative that was not reinforced (R2 in context A, and R1 in context B) in the Association Test of Experiment 4. Error bars represent the standard error of the mean

differences at testing could be based on the differential association between the context and the specific response trained within the contexts. This analysis suggests that participants had established an association between the context and the reinforced response during discriminative training that may be the basis of the deleterious effect of changing the context on performance in this experiment.

\section{General discussion}

The main goal of this study was to explore whether contexts concurrently enter into multiple binary associations with the rest of the elements of an instrumental conditioning situation in which switching the context after short training usually leads to deleterious effects on performance (Experiments 1 and 4). This study found results consistent with the idea that context-outcome (Experiment 2), context-discriminative stimulus (Experiment 3), and context-instrumental response (Experiment 4) binary associations were established within the same discriminative training. These results are in agreement with previous studies in human instrumental conditioning showing that participants establish all the possible associations among discriminative stimuli, responses and outcomes, as it seems to be the case with the context in the present experimental series (see Gámez \& Rosas, 2007).

Once shown that the context concurrently enters into associations with the outcome, the stimulus and the response, the deleterious effect on performance of switching the context could be explained by interference with any or several of these associations, depending on factors that are yet to be determined. In agreement with this result, one of the goals of future research on the mechanisms underlying contextual control should be to explore the conditions leading to 
contextual control by one association or the other, rather than focusing only on the conditions that lead to the formation of different associations.

For instance, León et al. (2010b) used a design that equated contexts-outcome and contexts-response relationships, leaving the break of the context-stimulus association with the context change as one likely candidate for explaining the contextswitch effect reported in their study. Although only the design used in Experiment 4 here equated context-outcome associations, the contribution of context-outcome association to the context-switch effect seems negligible here, as shown by the asymmetry of context-switch effects on reinforced and unreinforced discriminative stimuli reported in Experiment 1. Thus, context-switch effects in this situation may be explained by the severing of either or both, context-stimulus and context-response associations with the context change, given that results of Experiments 3 and 4 seem to suggest that those associations are established under the present training conditions.

The demonstration that participants established context-outcome (Experiment 2), context-stimulus (Experiment 3), and context-response (Experiment 4) associations does not ensure that interfering with any of those associations underlies the specific context-switch effects reported here. Some of those effects may be explained by assuming that either participants establish a configuration between the context and the discriminative stimulus (e.g., Pearce, 1987; Wagner, 2003), or by assuming that they establish a hierarchical association in which the context plays the role of an occasion setter (e.g., Bouton \& Swartzentruber, 1986; see Pearce \& Bouton, 2001). Interestingly, this latter role of the context as an occasion setter has been claimed as the only one underlying pure renewal effects (Nelson, Sanjuan, Vadillo-Ruiz, \& León, 2011). However, the experimental design used in these experiments makes it difficult to claim that either configural or hierarchical learning plays a relevant role on the context-switch effects reported in these series. Note that this study is focused on context-switch effects that appear after short training, and that both, configural and hierarchical learning seem to need of long periods of training to develop. For instance, Giurfa, Schubert, Reisenman, Gerber, and Lachnit (2003) found that the use of elemental or configural strategies to solve a visual discrimination in bees depended on the length of training, so that configural strategies would develop only after long training with the discrimination. Similarly, the feature positive occasion setting that may underlie the contextswitch effect reported here has been found to require a large amount of training in nonhuman animals, and even under optimal conditions designed to produce it, sometimes this effect is not observed (see Bouton \& Nelson, 1998). Similarly, studies with human participants suggest that establishing the modulatory role of stimuli may be quite difficult (e.g., Baeyens et al., 1998; Baeyens et al., 2005; Declercq \& De Houwer, 2001). Thus, even though the role of more complex associations involving the context cannot be discarded with the data reported here, it seems more parsimonious to explain the context-switch effects reported in studies involving short training by the loss of the contribution to performance of one or several of the simple binary associations like the ones found in this study.

In summary, this experimental series has found evidence suggesting that context-outcome, context-stimulus, and context-response associations are concurrently established within short training of an instrumental discrimination in humans, showing that in a given situation multiple associations are simultaneously established has important consequences for the understanding of contextual control of behavior. For instance, discussions about the mechanism underlying renewal from extinction (e.g., Bouton, 1993; Nelson et al., 2001) should not be so much based on which mechanisms are established during the renewal procedure, but in which ones are expressed. It then remains to agree on whether the definition of a phenomenon should be based on the expressed mechanism, or in the expressed behavior (see for instance, Nelson et al., 2011; Polack, Laborda \& Miller, 2013).

Most importantly, these associations are not necessary to solve the discrimination, given that discriminative training designs used here allowed for solving the task without using the contexts. As it may be observed in Table 1, the task could be solved by learning that $\mathrm{R} 1$ is followed by the outcome whenever discriminative stimulus $\mathrm{X}$ was present in Experiment 4 participants had to learn also that R2 was reinforced in the presence of $\mathrm{Y}$. Contexts $\mathrm{A}$ and $\mathrm{B}$ were redundant to solve the task. This is not to say that contexts were irrelevant to solve the task from the point of view of the participant, and in fact in Experiments 1-3 they were informative about the presence of the outcome, and this might favor participants to take the contexts in account, something that perhaps would not occur in a situation in which contexts were actually irrelevant to solve the task. Further research will be needed to explore whether the role played by redundant contexts may be extended or not to irrelevant contexts.

Finally, the results of these experiments show that redundant contexts quickly enter into binary associations with the elements of instrumental conditioning, and that these associations may control performance afterwards. Once shown that contexts enter into different associations with the elements of a given situation, future research should focus on establishing the conditions that lead context-switch effects to be explained by interference with one or several of these associations. 
Author note This research was funded by Grants PSI2010-15215 from the Spanish Ministry of Science and Innovation, and PSI2014-52263-C21-P from the Spanish Ministry of Economy and Competitiveness.

\section{References}

Baddeley, A. D. (1982). Domains of recollection. Psychological Review, 89, 708-729. doi:10.1037//0033-295X.89.6.708

Baeyens, F., Hendrickx, H., Crombez, G., \& Hermans, D. (1998). Neither extended sequential nor simultaneous feature positive training result in modulation of evaluative flavor conditioning in humans. Appetite, 31, 185-204. doi:10.1006/appe.1998.0167

Baeyens, F., Vansteenwegen, D., Beckers, T., Hermans, D., Kerkhof, I., \& Ceulaer, A. (2005). Extinction and renewal of Pavlovian modulation in human sequential Feature Positive discrimination learning. Learning \& Memory, 12, 178-192. doi:10.1101/1m.89905

Bouton, M. E. (1993). Context, time, and memory retrieval in the interference paradigms of Pavlovian learning. Psychological Bulletin, 114, 80-99. doi:10.1037/0033-2909.114.1.80

Bouton, M. E. (1994). Conditioning, remembering, and forgetting. Journal of Experimental Psychology: Animal Behavior Processes, 20, 219-231. doi:10.1037/0097-7403.20.3.219

Bouton, M. E. (2004). Context and behavioral processes in extinction. Learning and Memory, 11, 485-494. doi:10.1101/lm.78804

Bouton, M. E. (2010). The multiple forms of "context" in associative learning theory. In B. Mesquita, L. Feldman Barrett, \& E. Smith (Eds.), The mind in context (pp. 233-258). New York: The Guilford Press.

Bouton, M., Frohardt, R., Sunsay, C., Waddell, J., \& Morris, R. (2008). Contextual control of inhibition with reinforcement: Adaptation and timing mechanisms. Journal of Experimental Psychology: Animal Behavior Processes, 34, 223-236. doi:10.1037/0097-7403.34.2.223

Bouton, M. E., \& Nelson, J. B. (1998). Mechanisms of feature-positive and feature-negative discrimination learning in an appetitive conditioning paradigm. In N. A. Schmajuk, \& P. C. Holland (Eds.), Occasion setting: Associative learning and cognition in animals (pp. 69-112). Washington, DC, US: American Psychological Association. http://dx.doi.org/10.1037/10298-003

Bouton, M. E., \& Swartzentruber, D. (1986). Analysis of the associative and occasion-setting properties of contexts participating in a Pavlovian discrimination. Journal of Experimental Psychology: Animal Behavior Processes, 12, 333-350. doi:10.1037/0097-7403.12.4.333

Colwill, R. M. (1994). Associative representations of instrumental contingencies. The Psychology of Learning and Motivation, 31, 1-72. doi:10.1016/S0079-7421(08)60408-9

Colwill, R. M., \& Motzkin, D. K. (1994). Encoding of the unconditioned stimulus in Pavlovian conditioning. Animal Learning \& Behavior, 22, 384-394. doi:10.3758/BF03209158

Colwill, R. M., \& Rescorla, R. A. (1988). Associations between the discriminative stimulus and the reinforcer in instrumental learning. Journal of Experimental Psychology: Animal Behavior Processes, 14, 155-164. doi:10.1037/0097-7403.14.2.155

Darby, R. J., \& Pearce, J. M. (1995). Effects of context on responding during a compound stimulus. Journal of Experimental Psychology: Animal Behavior Processes, 21, 143-154. doi:10.1037/0097-7403.21.2.143

Declercq, M., \& De Houwer, J. (2011). Evidence against an occasion setting account of avoidance learning. Learning and Motivation, 42, 46-52. doi:10.1016/j.lmot.2010.08.007

Delamater, A. R. (1996). Effects of several extinction treatments upon the integrity of Pavlovian stimulus-outcome associations. Animal Learning \& Behavior, 24, 437-449. doi:10.3758/BF03199015
Gámez, A. M., Martos, R., Abad, M. J. F., \& Rosas, J. M. (2013). Associative relationships in human predictive learning. Spanish Journal of Psychology, 16, 1-11. doi:10.1017/sjp.2013.7

Gámez, A. M., \& Rosas, J. M. (2005). Transfer of stimulus control across instrumental responses is attenuated by extinction in human instrumental conditioning. International Journal of Psychology and Psychological Therapy, 5, 265-308. Retrieved from http://www. ijpsy.com/volumen5/num3/120/transfer-of-stimulus-control-acrossinstrumental-EN.pdf

Gámez, A. M., \& Rosas, J. M. (2007). Associations in human instrumental conditioning. Learning and Motivation, 38, 242-261. doi:10.1016/j.lmot.2006.11.001

Giurfa, M., Schubert, M., Reisenman, C., Gerber, B., \& Lachnit, H. (2003). The effect of cumulative experience on the use of elemental and configural visual discrimination strategies in honeybees. Behavioural Brain Research, 145, 161-169. doi:10.1016/S01664328(03)00104-9

Glautier, S. (2004). Asymmetry of generalization decrement in causal learning. Quarterly Journal of Experimental Psychology Section B, 57, 315-329. doi:10.1080/02724990344000169

Godden, D. R., \& Baddeley, A. D. (1975). Context-dependent memory in two natural environments: On land and underwater. British Journal of Psychology, 66, 325-331. doi:10.1111/j.2044-8295.1975. tb01468.x

Holland, P. C. (1983). "Occasion-setting" in Pavlovian feature positive discriminations. In M. L. Commons, R. J. Herrnstein, \& A. R. Wagner (Eds.), Quantitative analyses of behavior: Volume 4. Discrimination processes (pp. 183-206). Cambridge: Ballinger.

León, S. P., Abad, M. J. F., \& Rosas, J. M. (2010a). Giving contexts informative value makes information context specific. Experimental Psychology, 57, 46-53. doi:10.1027/1618-3169/a000006

León, S. P., Abad, M. J. F., \& Rosas, J. M. (2010b). The effect of context change on simple acquisition disappears with increased training. Psicológica, 31, 49-63. Retrieved from http://www.uv. es/revispsi/articulos1.10/3LEON.pdf

León, S. P., Abad, M. J. F., \& Rosas, J. M. (2011). Context-outcome associations mediate context-switch effects in a human predictive learning task. Learning and Motivation, 42, 84-98. doi:10.1016/j. lmot.2010.10.001

León, S. P., Callejas-Aguilera, J. E., \& Rosas, J. M. (2012). Context switch effects and context experience in rat's conditioned taste aversion. Psicológica, 33, 15-38. Retrieved from http://www.uv. es/revispsi/articulos1.12/2LEON.pdf

Mackintosh, N. (1975). A theory of attention: Variations in the associability of stimuli with reinforcement. Psychological Review, 82, 276-298. doi:10.1037/h0076778

Miguez, G., Witnauer, J. E., Laborda, M. A., \& Miller, R. R. (2014). Trial spacing during extinction: The role of context-US associations. Journal of Experimental Psychology: Animal Learning and Cognition, 40, 81-91. doi:10.1037/a0033203

Moreno-Fernández, M. M., Abad, M. J. F., Ramos-Álvarez, M. M., \& Rosas, J. M. (2011). Context-outcome associations underlie contextswitch effects after partial reinforcement in human predictive learning. Psicológica, 32, 367-383. Retrieved from http://www.uv. es/revispsi/articulos2.11/11MORENOFDEZ.pdf

Murphy, R. A., Baker, A. G., \& Fouquet, N. (2001). Relative validity of contextual and discrete cues. Journal of Experimental Psychology: Animal Behavior Processes, 27, 59-67. doi:10.1037/00977403.27.2.137

Nadler, N., Delgado, M. R., \& Delamater, A. R. (2011). Pavlovian to instrumental transfer of control in a human learning task. Emotion, 11, 1112-23. doi:10.1037/a0022760

Nelson, J. B. (2002). Context specificity of excitation and inhibition in ambiguous stimuli. Learning and Motivation, 33, 284-310. doi:10.1006/lmot.2001.1112 
Nelson, J. B., Sanjuan, M. C., Vadillo-Ruiz, S., Pérez, J., \& León, S. P. (2011). Experimental renewal in human participants. Journal of Experimental Psychology. Animal Behavior Processes, 37, 58-70. doi:10.1037/a0020519

Paredes-Olay, C., Abad, M. J. F., Gámez, M., \& Rosas, J. M. (2002). Transfer of control between causal predictive judgments and instrumental responding. Animal Learning \& Behavior, 30, 239-248. doi:10.3758/BF03192833

Pearce, J. M. (1987). A model for stimulus generalization in Pavlovian conditioning. Psychological Review, 94, 61-73. doi:10.1037/0033295X.94.1.61

Pearce, J. M., \& Bouton, M. E. (2001). Theories of associative learning in animals. Annual Review of Psychology, 52, 111-139. Retrieved from http://psych.cf.ac.uk/home2/pearce/Annual\%20Rev\%20 of\%20Psych\%20-\%2052\%20-\%20111-139.pdf

Pearce, J. M., \& Hall, G. (1980). A model for Pavlovian learning: Variations in the effectiveness of conditioned but not of unconditioned stimuli. Psychological Review, 87, 532-552. doi:10.1037//0033-295X.87.6.532

Pickens, C. L., Golden, S. A., Adams-Deutsch, T., Nair, S. G., \& Shaham, Y. (2009). Long-lasting incubation of conditioned fear in rats. Biological Psychiatry, 65, 881-886. doi:10.1016/j.biopsych.2008.12.010

Rescorla, R. A. (1991). Associations of multiple outcomes with an instrumental response. Journal of Experimental Psychology: Animal Behavior Processes, 17, 465-474. doi:10.1037/0097-7403.17.4.465

Rescorla, R. A. (1992). Associations between an instrumental discriminative stimulus and multiple outcomes. Journal of Experimental Psychology: Animal Behavior Processes, 18, 95-104. doi:10.1037/0097-7403.18.1.95

Rescorla, R. A., \& Wagner, A. R. (1972). A theory of Pavlovian conditioning: Variations in the effectiveness of reinforcement and nonreinforcement. In A. H. Black \& W. F. Prokasy (Eds.), Classical conditioning II: Current research and theory (pp. 64 99). New York: Appleton-Century-Crofts.

Rosas, J. M., García-Gutiérrez, A., \& Callejas-Aguilera, J. E. (2007). $\mathrm{AAB}$ and $\mathrm{ABA}$ renewal as a function of the number of extinction trials in conditioned taste aversion. Psicológica, 28, 129-150. Retrieved from http://www.uv.es/revispsi/articulos2.07/2ROSAS. pdf

Rosas, J. M., Todd, T. P., \& Bouton, M. E. (2013). Context change and associative learning. Wiley Interdisciplinary Reviews: Cognitive Science, 4, 237-244. doi:10.1002/wcs. 1225

Rosas, J. M., Vila, N. J., Lugo, M., \& López, L. (2001). Combined effect of context change and retention interval upon interference in causality judgments. Journal of Experimental Psychology: Animal Behavior Processes, 27, 153-164. doi:10.1037/0097-7403.27.2.153

Tulving, E., \& Osler, S. (1968). Effectiveness of retrieval cues in memory for words. Journal of Experimental Psychology, 77, 593-601. doi:10.1037/h0026069

Urcelay, G. P., \& Miller, R. R. (2010). Two roles of the context in Pavlovian fear conditioning. Journal of Experimental Psychology: Animal Behavior Processes, 36, 268-280. doi:10.1037/a0017298

Urcelay, G. P., \& Miller, R. R. (2014). The functions of contexts in associative learning. Behavioral Processes, 104, 2-12. doi:10.1016/j.beproc

Urcelay, G. P., Witnauer, J. E., \& Miller, R. R. (2012). The dual role of the context in postpeak performance decrements resulting from extended training. Learning and Behavior, 40, 476-93. doi:10.3758/s13420012-0068-4

Wagner, A. R. (2003). Context-sensitive elemental theory. Quarterly Journal of Experimental Psychology, 23B, 7-29. doi:10.1080/02724990244000133 